\title{
DIABETIC MOTHERS; \\ FREQUENCY OF MACROSOMIA AND HYPOGLYCEMIA IN NEONATES OF (CONTROLLED VERSUS UNCONTROLLED).
}

1. MBBS, FCPS,

Assistant Professor,

Department of Pediatrics,

LUMHS, Jamshoro.

2. MBBS, FCPS,

Assistant Professor

Department of Pediatrics

Muhammad Medical College,

Mirpurkhas.

3. MBBS, FCPS,

Senior Registrar,

Department of Pediatrics,

LUMHS, Jamshoro.

Gurmeet Medical Centre Soomra

Mohalla,

Tando Muhammad Khan, Sindh.

4. MBBS, DCH, FCPS,

Professor of Pediatrics,

Head of Pediatric Department

Liaquat National Hospital Karachi.

Correspondence Address:

Dr. Muhammad Nadeem Chohan

House No. A-251 Phase-1 Sindh

University Housing Employee

Cooperative Society Jamshoro, Sindh.

nadeem.chohan@lumhs.edu.pk

Article received on:

27/05/2017

Accepted for publication:

15/10/2017

Received after proof reading:

$29 / 11 / 2017$

\section{INTRODUCTION}

Diabetes is one of the commonest and important metabolic disorders that affect the health of pregnant women and infants. ${ }^{1}$ About $3-10 \%$ of all pregnancies are complicated by diabetes. ${ }^{2}$ Maternal diabetes is a significant cause of shortterm and long-term morbidity for the infant and the mother. Fetal complications are more frequent in patients with pre-existing diabetes than those with gestational diabetes. Early diagnosis of preexisting diabetes warrants early treatment and a strict clinical follow-up since early intervention has been shown to improve fetal and maternal outcomes in randomized controlled trials. ${ }^{1}$

Women with diabetes seeking to conceive strive to achieve blood glucose and hemoglobin A1C $(\mathrm{HbA} 1 \mathrm{C})$ levels as close to normal as possible when they can be safely achieved without undue

\begin{abstract}
Muhammad Nadeem Chohan', Imran Ahmed ${ }^{2}$, Deve Dass ${ }^{3}$, Samina Shamim ${ }^{4}$ Cross-Sectional Study. Place and duration of Study: Ante-natal Clinic, Labor Room and Post Natal Unit of Pediatric Department, Liaquat National Hospital Karachi, from October 2013 to March 2014 over 376 neonates. Methodology: This study was carried out on 376 cases at 列 was 35.37 years, male prevalence was found higher, and that is $57.40 \%$. Mean gestational while diabetes. Frequency of hypoglycemia was found in $21.50 \%$ patients, while . Conclusion: The frequency of hypoglycemia and
\end{abstract} Infant of Diabetic Mother, Hypoglycemia, Hyperglycemia, Macrosomia. Neonates. of macrosomia and hypoglycemia in neonates of (controlled versus uncontrolled).. Professional Med J 2017;24(12):1872-1877. DOI:10.17957/TPMJ/17.4083 hypoglycemia. ${ }^{3}$ There should be self-monitoring of blood glucose in all pregnant women with gestational or overt diabetes ${ }^{4}$ and testing before and either 1 or 2 hours after the start of each meal, as indicated, at bedtime and during the night. ${ }^{3}$ Pregnant women with overt or gestational diabetes strive to achieve a target pre-prandial blood glucose $\leq 95 \mathrm{mg} / \mathrm{dL}^{4}$, and levels 1 hour after the start of a meal $\leq 140 \mathrm{mg} / \mathrm{dL}(7.8 \mathrm{mmol} / \mathrm{L})$ and 2 hours after the start of a meal $\leq 120 \mathrm{mg} /$ $\mathrm{dL}(6.7 \mathrm{mmol} / \mathrm{L})$ when these targets can be safely achieved without undue hypoglycemia. Women with overt diabetes strive to achieve a HbA1C $\leq 7 \%$ (ideally $\leq 6.5 \%$ ). ${ }^{3}$ Women with diabetes who receive preconception counseling have better preconception glycemic control and are more likely to have favorable pregnancy outcomes. ${ }^{5}$

Various previous studies shows association 
between maternal diabetes and neonatal hypoglycemia and macrosomia but those were lacking the monitoring and management from very beginning of pregnancy, hence this study is done from initial days of pregnancy to make it more suitable. This study is also done to see the impact of blood glucose control during pregnancy in known pre-gestational diabetic women over blood glucose level and birth weight of newborn, as previous studies dose not touch this concept, hence to enforce the control of blood sugar level during pregnancy to prevent the neonatal hypoglycemia and macrosomia.

\section{OBJECTIVE}

To compare the frequency of macrosomia and hypoglycemia in neonates born to Pregestational diabetic mothers having controlled versus uncontrolled diabetes during pregnancy at Liaquat National Hospital Karachi

\section{METHODOLOGY}

It was a Descriptive and Cross- Sectional Study done with Non Probability Consecutive.

Technique, conducted at Gynecology OPD, the labor room and post natal unit of Liaquat National Hospital Karachi, from October 2013 to March 2014 over 376 neonates.

Pregnant women who came at Gynecology OPD for antenatal checkup and having Type 1 or Type 2 Diabetes were enrolled in the study. History was taken for the duration of diabetes and methods of its control. They were counseled for proper management to control their blood sugar level by life style modifications, dietary advice, insulin or oral medications. Blood Sugar documentation card was given to document the blood sugar level, both fasting and postprandial 3 times a week, while Hemoglobin $\mathrm{C}$ was recorded every 3 monthly. They were assessed again at post natal unit to check her pregnancy record, i.e. checked for control of blood sugar level and Hemoglobin A1C level.

Capillary blood was taken with the help of lancet prick and glucose level checked from the heel of the newborn using glucose reagent strips at
30 minutes after birth. In case of hypoglycemia mother feed was given and top feed was given in case of non-availability of mother feed.

Neonatal birth weight taken immediately after birth and plotted on growth chart for the assessment of macrosomia. All this data was collected and recorded by main researcher in predesigned proforma. Informed verbal consent was taken prior to asking questions and the information gathered from mothers was kept confidential. This study was done after taking the approval from Research Ethical Review Committee of Hospital.

The data entered and analyzed in statistical program SPSS version 16.0. Frequencies and percentages computed for qualitative variables like gender of baby, hypoglycemia (neonatal Glucose level), Macrosomia (weight of baby), Gravida, Para, whether diabetes controlled or uncontrolled, diabetes how controlled (Exercise, diet, Insulin), mode of delivery and duration of maternal diabetes.

The numerical variables such as age of mother (in years), gestational age of baby etc. presented as Mean \pm Standard deviation. Effect modifiers controlled by stratification of age of mother, duration of diabetes, gender of baby, gestational age of baby, parity and mode of delivery. Outcome compared among controlled and uncontrolled diabetic mothers applying chi square test. All the data calculated on $95 \%$ confidence interval. A pvalue $\leq 0.05$ considered as statistically significant level.

\section{Inclusion Criteria}

All alive babies born to known Diabetic Mothers (whether controlled or uncontrolled diabetes) above 28 weeks of gestation (Assessed on Last Menstrual Period), Duration of Maternal Diabetes of more than 1 year.

\section{Exclusion Criteria}

Babies born before 28 weeks of gestation (Assessed on Last Menstrual Period), Babies born to Nondiabetic mothers and babies born to gestational diabetic mothers. 


\section{Operational Definitions}

Diabetes: Diabetes may be defined as, that meeting the WHO criteria for diabetes that is Fasting plasma glucose level $>126 \mathrm{mg} / \mathrm{dl}$ at $2 \mathrm{~m}$ different occasions (24 hours apart)

Hypoglycemia:Any blood glucose levels of $<45 \mathrm{mg} / \mathrm{dl}(2.2 \mathrm{mmol} / \mathrm{l})$

Macrosomia: Birth weight $>90 \%$ for gestational age

Well controlled Diabetes: (Presence of either of the following)

Fasting blood glucose level $=<100 \mathrm{mg} / \mathrm{dl}$,

$$
\mathrm{HbA} 1 \mathrm{C}=<6.5 \%
$$

Uncontrolled Diabetes: (Presence of either of the following)

Fasting blood glucose level $=>100 \mathrm{mg} / \mathrm{dl}$,
$\mathrm{HbA} 1 \mathrm{C}=>6.5 \%$

\section{RESULTS}

Mean age of women was 35.37 years (Table-I). Most of the patient lies in age $<35$ years, that is $54.30 \%$ (Table-I). Male prevalence was found higher, that is $57.40 \%$ (Table-III). Mean gestational age was 37.22 weeks (Table-I). Most of the patient was present in $<40$ weeks of gestation that is $96.30 \%$ (Table-I). Mean duration of diabetes was 3.77 years (Table-IV). Most of the patients were present with duration of diabetes $>3$ years that is $59.30 \%$ (Table-V). The majority of the patients were present with multi gravida status that is $74.50 \%$, where as $77.70 \%$ patients were multiparous (Table-V \& VI).

\begin{tabular}{|l|c|c|c|c|}
\hline \multicolumn{1}{|c|}{ Age of Mothers (Years) } & Mean & \multicolumn{2}{|c|}{ Minimum } & Maximum \\
\hline Gestational age of Baby (Weeks) & $\mathbf{3 5 . 3 7}$ & $\mathbf{1 . 4 9}$ & 37 & $\mathbf{3 4}$ \\
\hline Duration of Diabetes (Years) & 37.22 & 1.13 & 2 & 43 \\
\hline
\end{tabular}

Table-I. Age parameters

\begin{tabular}{|c|c|c|c|c|c|}
\hline \multirow{2}{*}{\multicolumn{2}{|c|}{ Outcome }} & \multicolumn{2}{|c|}{ Diabetes Status } & \multirow{3}{*}{$\begin{array}{c}\text { Total } \\
81(100)\end{array}$} & \multirow{2}{*}{ P-Value } \\
\hline & & \multirow{2}{*}{$\begin{array}{c}\text { Uncontrolled } \\
66(81.5)\end{array}$} & \multirow{2}{*}{$\begin{array}{c}\text { Controlled } \\
15(18.5)\end{array}$} & & \\
\hline \multirow{3}{*}{ Hypoglycemia } & Yes & & & & \multirow{3}{*}{0.001} \\
\hline & No & $93(31.5)$ & $202(68.5)$ & $295(100)$ & \\
\hline & Total & 159 (42.3) & $217(57.7)$ & $376(100)$ & \\
\hline \multirow{3}{*}{ Macrosomia } & Yes & $111(81.6)$ & $25(18.4)$ & $136(100)$ & \multirow{3}{*}{0.001} \\
\hline & No & $48(20)$ & $192(80)$ & $240(100)$ & \\
\hline & Total & 159 (42.3) & $217(57.7)$ & $376(100)$ & \\
\hline
\end{tabular}

Table-II. Comparison of outcome and diabetes status $n=376$

\begin{tabular}{|c|c|c|c|c|c|}
\hline \multirow{2}{*}{ Gender } & \multirow{2}{*}{ Hypoglycemia } & \multicolumn{2}{|c|}{ Diabetes Status } & \multirow{2}{*}{ Total } & \multirow{2}{*}{ P- Value } \\
\hline & & Uncontrolled & Controlled & & \\
\hline \multirow{3}{*}{ Male } & Yes & $36(92.3)$ & $3(7.7)$ & $39(100)$ & \multirow{3}{*}{0.001} \\
\hline & No & $17(9.6)$ & $160(90.4)$ & $177(100)$ & \\
\hline & Total & $53(24.5)$ & 163 (75.5) & $216(100)$ & \\
\hline \multirow{3}{*}{ Female } & Yes & 30 (71.4) & $12(28.6)$ & $42(100)$ & \multirow{3}{*}{0.452} \\
\hline & No & $76(64.4)$ & 42 (35.6) & $118(100)$ & \\
\hline & Total & 106 (66.2) & $54(33.8)$ & $160(100)$ & \\
\hline
\end{tabular}

Table-III. Comparison of hypoglycemia and diabetes status with gender of the baby

\begin{tabular}{|c|c|c|c|c|c|}
\hline \multirow{2}{*}{ Gender } & \multirow{2}{*}{ Macrosomia } & \multicolumn{2}{|c|}{ Diabetes Status } & \multirow{2}{*}{ Total } & \multirow{2}{*}{ P-Value } \\
\hline & & Uncontrolled & Controlled & & \\
\hline \multirow{3}{*}{ Male } & Yes & $53(94.6)$ & $3(5.4)$ & $56(100)$ & \multirow{3}{*}{0.001} \\
\hline & No & $0(0)$ & $160(75.5)$ & $160(100)$ & \\
\hline & Total & $53(24.5)$ & 163 (75.5) & $216(100)$ & \\
\hline \multirow{3}{*}{ Female } & Yes & $58(72.5)$ & $22(27.5)$ & $80(100)$ & \multirow{3}{*}{0.132} \\
\hline & No & $48(60)$ & $32(40)$ & $80(100)$ & \\
\hline & Total & $106(66.2)$ & $54(33.8)$ & $160(100)$ & \\
\hline
\end{tabular}




\begin{tabular}{|c|c|c|c|c|c|}
\hline \multirow{2}{*}{$\begin{array}{l}\text { Age Group } \\
\text { (Years) }\end{array}$} & \multirow{2}{*}{ Hypoglycemia } & \multicolumn{2}{|c|}{ Diabetes Status } & \multirow{2}{*}{ Total } & \multirow{2}{*}{ P-Value } \\
\hline & & Uncontrolled & Controlled & & \\
\hline \multirow{3}{*}{$\leq 35$} & Yes & $30(81.1)$ & $7(18.9)$ & $37(100)$ & \multirow{3}{*}{0.001} \\
\hline & No & 50 (29.9) & $117(70.1)$ & $167(100)$ & \\
\hline & Total & $80(39.2)$ & $124(60.8)$ & 204 (100) & \\
\hline \multirow{3}{*}{$>35-40$} & Yes & 36 (81.8) & $8(18.2)$ & $44(100)$ & \multirow{3}{*}{0.001} \\
\hline & No & $43(33.6)$ & $85(66.4)$ & $128(100)$ & \\
\hline & Total & 79 (45.9) & $93(54.1)$ & $172(100)$ & \\
\hline \multirow{3}{*}{$>40$} & Yes & $4(80)$ & $1(20)$ & $5(100)$ & \multirow{3}{*}{0.001} \\
\hline & No & $2(22.2)$ & $7(77.8)$ & $9(100)$ & \\
\hline & Total & $6(42.9)$ & $8(57.1)$ & $14(100)$ & \\
\hline \multirow{3}{*}{$\begin{array}{l}\text { Diabetes Duration } \\
\leq 3 \text { Years }\end{array}$} & Yes & $11(55)$ & $9(45)$ & $20(100)$ & \multirow{3}{*}{0.001} \\
\hline & No & $23(17.3)$ & $110(82.7)$ & $133(100)$ & \\
\hline & Total & 34 (22.3) & $119(77.8)$ & $153(100)$ & \\
\hline \multirow{3}{*}{$\begin{array}{l}\text { Diabetes Duration } \\
>3 \text { Years }\end{array}$} & Yes & 55 (90.2) & $6(9.8)$ & $61(100)$ & \multirow{3}{*}{0.001} \\
\hline & No & 70 (43.2) & $92(56.8)$ & $162(100)$ & \\
\hline & Total & $125(56.1)$ & $98(43.9)$ & $223(100)$ & \\
\hline \multirow{3}{*}{ Primiparous } & Yes & $36(100)$ & $0(0)$ & $36(100)$ & \multirow{3}{*}{0.001} \\
\hline & No & $17(35.4)$ & $31(64.6)$ & $48(100)$ & \\
\hline & Total & $53(63.1)$ & $31(36.9)$ & $84(100)$ & \\
\hline \multirow{3}{*}{ Multiparous } & Yes & $30(66.7)$ & 15 (33.3) & $45(100)$ & \multirow{3}{*}{0.001} \\
\hline & No & $76(30.8)$ & $171(69.2)$ & $247(100)$ & \\
\hline & Total & $106(36.3)$ & $186(63.7)$ & $292(100)$ & \\
\hline
\end{tabular}

Table-V. Comparison of hypoglycemia and diabetes status with age, diabetes duration and parity $\mathrm{n}=376$

\begin{tabular}{|c|c|c|c|c|c|}
\hline \multirow{2}{*}{$\begin{array}{l}\text { Age Group } \\
\text { (Years) }\end{array}$} & \multirow{2}{*}{ Macrosomia } & \multicolumn{2}{|c|}{ Diabetes Status } & \multirow{2}{*}{ Total } & \multirow{2}{*}{ P-Value } \\
\hline & & Uncontrolled & Controlled & & \\
\hline \multirow{3}{*}{$\leq 35$} & Yes & 54 (78.3) & $15(21.7)$ & $69(100)$ & \multirow{3}{*}{0.001} \\
\hline & No & $26(19.3)$ & $109(80.7)$ & $135(100)$ & \\
\hline & Total & $80(39.2)$ & $124(60.8)$ & $204(100)$ & \\
\hline \multirow{3}{*}{$>35$} & Yes & $57(85.1)$ & $10(14.9)$ & $67(100)$ & \multirow{3}{*}{0.001} \\
\hline & No & $22(21)$ & $83(79)$ & $105(100)$ & \\
\hline & Total & 79 (45.9) & $93(54.1)$ & $172(100)$ & \\
\hline \multirow{3}{*}{$>40$} & Yes & $4(80)$ & $1(20)$ & $5(100)$ & \multirow{3}{*}{0.001} \\
\hline & No & $2(22.2)$ & $7(77.8)$ & $9(100)$ & \\
\hline & Total & $6(42.9)$ & $8(57.1)$ & $14(100)$ & \\
\hline \multirow{3}{*}{$\begin{array}{l}\text { Diabetes Duration } \\
\leq 3 \text { Years }\end{array}$} & Yes & $30(66.7)$ & 15 (33.3) & $45(100)$ & \multirow{3}{*}{0.001} \\
\hline & No & $4(3.7)$ & $104(96.3)$ & $108(100)$ & \\
\hline & Total & 34 (22.3) & $119(77.8)$ & $153(100)$ & \\
\hline \multirow{3}{*}{$\begin{array}{l}\text { Diabetes Duration } \\
>3 \text { Years }\end{array}$} & Yes & $81(89)$ & $10(11)$ & 91 (100) & \multirow{3}{*}{0.001} \\
\hline & No & 44 (33.3) & $88(66.7)$ & $132(100)$ & \\
\hline & Total & $125(56.1)$ & $98(43.9)$ & $223(100)$ & \\
\hline \multirow{3}{*}{ Primiparous } & Yes & $53(100)$ & $0(0)$ & $53(100)$ & \multirow{3}{*}{0.001} \\
\hline & No & $0(0)$ & $31(64.6)$ & $31(100)$ & \\
\hline & Total & $53(63.1)$ & 31 (36.9) & $84(100)$ & \\
\hline \multirow{3}{*}{ Multiparous } & Yes & 58 (69.9) & $25(30.1)$ & $83(100)$ & \multirow{3}{*}{0.001} \\
\hline & No & $48(23)$ & $161(77)$ & 209 (100) & \\
\hline & Total & $106(36.3)$ & $186(63.7)$ & $292(100)$ & \\
\hline
\end{tabular}

Table-VI. Comparison of macrosomia and diabetes status with age, diabetes duration and parity $n=376$ 
Frequency of hypoglycemia was found in $21.50 \%$ patients, while macrosomia was found in $36.20 \%$ patients (Table-II). Stratification was done to see the effect of diabetes status on the outcome. Chi square test was applied and significant effect was observed as P-Value was found 0.001 in hypoglycemia and macrosomia (Table-V). Effect modifiers were controlled by stratification of age, gestational age, duration of diabetes, gender of the baby and parity.

\section{DISCUSSION}

Hypoglycemia is the most common cause of morbidity in the Infants of Diabetic Mothers and can be a challenging and protracted problem to manage. In our study the hypoglycemia was noted in (81) $21.5 \%$, which is supported by other similar studies conducted locally in Peshawar that showed $23.8 \%$ hypoglycemic neonates. ${ }^{2}$

Macrosomia is another major complication of the diabetic pregnancies. In this study total (136) $36.2 \%$ Infants of Diabetic Mothers were macrocosmic, (both uncontrolled and controlled diabetes during pregnancy), while a similar study from Hyderabad showed macrosomia was seen in $41.8 \%$ of fetuses. ${ }^{8}$

Another study from Hyderabad showed macrosomia 34\% neonates. ${ }^{9}$ Another study from Saudi Arabia showed $8.2 \%$ macrocosmic neonates ${ }^{6}$, as $18.4 \%$ neonates in our study had macrosomia who born to mothers with controlled diabetes during pregnancy, that suggest the possibility of tight glycemic control in Saudi Arabian study. Another local study from Islamabad reported a relatively lower occurrence of macrosomia (28\%), which may be due to a better glycemic control in mothers. As strict metabolic control with insulin in mothers with gestational diabetes mellitus has proven to attenuate the risk of LGA (macrosomia).

In our study Neonatal Hypoglycemia was most common in babies of uncontrolled diabetic mothers 66 (81.5), while 15 (18.5\%) neonates had hypoglycemia who born to mothers with controlled diabetes during pregnancy, A similar study from Saudi Arabia showed neonatal hypoglycemia in $19(24.4 \%)$ neonates ${ }^{10}$, although this study was done only on gestational diabetic mother but results are similar. A local study from Islamabad showed hypoglycemia in $28 \%$ of cases whose mother's blood sugar was not controlled during pregnancy. ${ }^{11}$

Macrosomia was most common in neonates born to mothers having uncontrolled diabetes during pregnancy 111 (81.6), while 25 (18.4) neonates had hypoglycemia at birth, who born to mothers having controlled diabetes during pregnancy, while much better results were obtained in a study from Saudi Arabia that showed macrosomia in 9(11.5) neonates born to controlled diabetes during pregnancy. ${ }^{10}$

In our study hypoglycemia was more common in male neonates $36(92.3 \%)$ as compared to female neonates $30(71.4 \%)$, while male neonates of controlled diabetic mothers had less 3 (7.7\%) neonatal hypoglycemia as compared to female neonates 12 (28.6\%). There was no difference in macrosomia in males $53(94.6 \%)$ and females 58 $(72.5 \%)$, of uncontrolled diabetic mothers, while more females $22(27.5 \%)$ were macrocosmic as compared to males 3 (5.4\%).

Maternal age more than 40 years had less neonatal hypoglycemia $4(80 \%)$ as compared to less than 40 years age $36(81.8 \%)$ in babies of uncontrolled diabetic mothers, while babies of controlled diabetic mothers (Less than 40 years of age) has neonatal hypoglycemia in $1(20 \%)$. Mothers whose diabetic control was $>3$ years before pregnancy and had uncontrolled diabetes during pregnancy born 55 (90.2\%) newborns with hypoglycemia, while women who had diabetes $<3$ years before pregnancy had only 11 (55\%) hypoglycemic neonates.

Parity had no association with neonatal hypoglycemia in uncontrolled diabetic mothers, while in controlled multiparous diabetic mothers had more neonates 15 (33.3\%) neonates with hypoglycemia, while Primiparous had $0(0 \%)$ neonatal hypoglycemia. There was no difference in in macrosomia in neonates of uncontrolled diabetic mothers 111 (81.6\%) with age <40 
years and age $>40$ years 4 (80\%). Women who had diabetes $<3$ years before pregnancy and uncontrolled diabetes had 30 (66.7\%) macrocosmic newborns, while women who had diabetes $>3$ years had 81 (89.6\%) macrocosmic newborns.

\section{CONCLUSION}

The frequency of hypoglycemia and macrosomia in infants of diabetic mother was $21.5 \%$ and $36.50 \%$ respectively. There was a significant difference in the frequency of macrosomia and hypoglycemia in infants of diabetic mothers among well controlled versus uncontrolled diabetics.

\section{Copyright(C) 15 Oct, 2017.}

\section{REFERENCES}

1. Schneider AE, Rayfield EJ, Busta A, Gurevich Y. Diabetes in Pregnancy. In: Principles of Diabetes Mellitus: Springer US; 2010. p. 233-44.

2. Hussain M, Irshad M, Khattak AK, Khan B. Frequency of various neonatal complications in infants born to diabetic mothers. JPMI 2011;25(3):227-32.

3. Grading quality of evidence and strength of recommendations. BMJ . 2004 Jun 19;328(7454):149

4. Dietary Reference Intakes for Energy, Carbohydrate, Fiber, Fat, Fatty Acids, Cholesterol, Protein, and Amino Acids (Macronutrients). Washington, D.C.: National Academies Press; 2005.

5. Anwar A, Salih A, Masson E, Allen B, Wilkinson L, Lindow SW. The effect of pre-pregnancy counselling for women with pre-gestational diabetes on maternal health status. Eur J Obstet Gynecol Reprod Biol. 2011 Apr;155(2):137-9.

6. Nadir S, Jamil S, Hamid M. The prevalence of macrosomia in newborns and its association with maternal diabetes. J Med Sci. 2015;23(1):3-6.

7. Haider G, Zehra N, Anjum F, Munir AA. Perinatal outcome in diabetic mothers. 2009;1(1):8-12.

8. Nel CHAN. Original Article Fetal Outcome In Diabetic Pregnant Mothers At Isra Univeristy Hospital. 2012;2012:47-50.

9. Almarzouki a a. Pregnancy outcome with controlled gestational diabetes: Pakistan J Med Sci. 2012;28(5):887-90.

10. Haider S, Riaz S, Iqbal M, Shireen gul. Neonatal outcome of diabetic pregnancy. Ann pak int med sci. 2010;6(2):107-12.

\section{AUTHORSHIP AND CONTRIBUTION DECLARATION}

\begin{tabular}{|c|l|l|l|}
\hline Sr. \# & \multicolumn{1}{|c|}{ Author-s Full Name } & \multicolumn{1}{|c|}{ Contribution to the paper } & Author=s Signature \\
\hline 1 & M. Nadeem Chohan & $\begin{array}{l}\text { Conception, Design collection, } \\
\text { Assembly of data, Drafting. } \\
\text { Analysis, Interpretation of data. }\end{array}$ \\
3 & Imran Ahmed & Deve Dass & $\begin{array}{l}\text { Critical revision of article, } \\
\text { Statistical expertise. }\end{array}$ \\
4 & Samina Shamim & \begin{tabular}{l} 
Final approval of analysis. \\
\hline
\end{tabular} &
\end{tabular}

